\title{
NEURAL NETWORK PARADIGMS IN CRASH MODELING ON NON URBAN HIGHWAYS IN INDIA
}

\author{
C. Naveen Kumar $^{1}$, Dr. Manoranjan Parida ${ }^{2}$, Dr. S. S. Jain ${ }^{3}$ \\ ${ }^{1}$ Research Scholar, Department of Civil Engineering, Indian Institute of Technology Roorkee \\ Uttarakhand, India (cnaveenkh@gmail.com)
}
${ }^{2}$ Professor in Department of Civil Engineering and Head, CTRANS, Indian Institute of Technology Roorkee, Uttarakhand, India (mparida@gmail.com)

${ }^{3}$ Professor in Department of Civil Engineering, Indian Institute of Technology Roorkee Uttarakhand, India (profssjain@gmail.com)

\begin{abstract}
Engineers and researchers in the transportation discipline have tried to build safe roads following appropriate design standards, but traffic accidents are unavoidable. Patterns involved in crashes could be detected if accurate prediction models capable of automatic prediction of various traffic accidents are developed. These accident patterns can be useful to develop traffic safety control policies. To obtain the greatest possible accident reduction effects with limited budgetary resources, it is important that measures are based on scientific and objective surveys of the causes of accidents and severity of injuries.

A number of explanatory variables related to traffic and road geometry that contributes to accident occurrence can be identified and to develop accident prediction models. The accident prediction models reported in literature largely employ the fixed parameter modeling approach, where the magnitude of influence of an explanatory variable is considered to be fixed for any observation in the population.

The mixed traffic on Indian multilane highways comes with a lot of variability within, ranging from difference in vehicle types. This could result in variability in the effect of explanatory variables on accidents across locations.

The study aims to evaluate Road Safety of a section on four-lane National Highway (NH)-58 located in the state of Uttarakhand, India.

Artificial Neural Networks (ANNs) models with different training functions were employed to develop road traffic crash prediction system. ANN models with different training functions further with different number of layers and hidden neurons were trained and analysed. A total of 275 dataset were randomly divided for training, validation and testing. Results show Schawarz's Bayesian Criterion (SBC) for ANN3 and ANN7 models were -2.135 and 1.378 respectively and the calculated model Chi Square value (38.60 for ANN3 \& 23.971 for ANN7) were also lesser than the critical chi-square value(295.35) revealing the model fitted the data precisely. The results also showed that percentage of trucks in the traffic stream, spot speed
\end{abstract}


increased the likelihood of accident occurrence whereas adequate carriageway, shoulder and median widths decreases the occurrence of crashes.

Keywords: Soft computing traffic crash analysis, Levenberg - Marguardt Training function, Bayesian Regulisation Training funtion.

\section{INTRODUCTION}

In recent years, significant effort and money have been invested to enhance highway safety. As available funds decrease, the allocation of resources for safety improvement projects must yield the maximum possible return on investment. Identifying highway locations that have the highest potential for crash reduction with the implementation of effective safety counter measures is therefore an important step in achieving the maximum return on safety investment. An ongoing challenge to transportation engineers is to plan and operate the transportation system in such a way that it meets various societal objectives such as reducing travel time and enhancing safety. Over the years, there has been an unprecedented increase in road transportation and vehicular traffic in India due to an exponential growth in the economy and consumption habits, which has led to unsafe conditions on our highways. Casualties due to accidents on these roads are increasing year after year. The road accidents deaths and injuries are global phenomena but more sever situation in mixed traffic condition as prevailing on Indian multilane highways. Owing to the likely under-reporting of accidents, the real situation is likely to be much worse. To deteriorate the road safety further, there is habit of poor maintenance of vehicle, bad driving practice, lack of enforcement, casual attitude of road users and least concerned towards the basic road safety measures by road maintaining agencies.

Road safety has become a growing concern for the public in general and highway professional in particular as road accidents are a major source of loss of life. Further; the economic losses caused by property damage or lost of working days resulting from injuries fatality have been estimated at billions of rupees annually. Concept of quality management and sustainable safety have gained ground in the past two decades and may have been among the factors that led policymakers and project managers to realize the need for purely safetyoriented tools to reduce the occurrence of crashes.

Road safety is both a health and development issue of concern considering its magnitude and gravity and the consequent negative impacts on the economy, public health and the general welfare of the people, particularly those with low incomes. Road safety is a shared, multi-sectoral, responsibility of the government and a range of civil society stakeholders. The success of road safety strategies in all countries depends upon a broad base support and common action from all stakeholders.

In this paper the study aims to identify the most critical safety influencing variables on a section of four-lane National Highway-58 through mathematical models that explains the relationship between accident count and highway safety influencing variables. 


\section{GLOBAL SCENARIOS}

As per the Commission for Global Road Safety (2009), road traffic accidents kill an estimated 1.3 million people and injure 50 million people per year globally, and global road fatalities are forecast to reach 1.9 million by 2020. It is estimated that the number of deaths from road accidents in Asia is about 700,000 per year, accounting for more than half of the world's road fatalities even though Asia accounted for only $43 \%$ of the global vehicle population in 2007.

Global Status Report on Road Safety (June 2009) of the World Health organization cites data from the World Health Statistics which indicate that road traffic injuries would become the fifth highest leading cause of death, outranking diabetes mellitus, HIV/AIDS, certain form of cancers and tuberculosis, in 2030 as compared to its ninth position in 2004.

In view of above, the importance of road safety studies are being felt all around the world.

\section{ROAD SAFETY CONCERN IN INDIA}

With rapid increase industrializations, motorizations and multilane highways in India; the casualties due to accidents on the roads are increasing alarmingly year by year. The dominance of road transport will continue in India as it has in the rest of the world. The share of the movement of both passengers and goods is expected to increase further in the coming years with the full implementation of the current road development programs being undertaken in the country. Most of this high-speed road development programs is expected to be completed by 2015 .

Studies of the relationship between gross domestic product (GDP) per capita, growth of motor vehicles and road fatalities, have shown that fatality rates increase as GDP increases at relatively low levels of GDP per capita, but then start to decline with continued GDP growth. The peak position on this inverted U-shaped curve is not, however, immutable.

At present more than 500,000 accidents occur annually with about 130,000 people losing their life in these accidents. Besides fatalities, nearly 500,000 people suffer injuries in road accidents which lead to lifelong misery for the victim and family. Road Safety Study can ensure that various safety deficiencies in road are reviewed so that these can be taken care at appropriate stage of road design or operation in a cost effective way.

\section{RESEARCH OBJECTIVE}

The study aims to identify the most critical safety influencing variables of a section of four-lane National Highway-58 through artificial analytical model that predicts frequency of accident count accurately for the provided highway safety influencing variables. 


\section{DATA COLLECTION}

The Highway traverses mainly through a plain terrain of mostly agricultural and Industrial areas. Most of the Highway study segment falls in rural areas (approximately 85\%). The major urban areas falling in the selected study stretch are Meerut, Khatauli and Muzaffarnagar. The study has been done for newly constructed 4-Lane road between Km.75.00 to Km.130.00 to identify all safety deficiencies responsible for road accidents. The traffic data was collected from NHAI. The AADT for 2008 was 17810 and AADT for year 2011 is 22293 in PCU. Project details were also obtained from the highway agency.

Road safety influencing variables conditions were found through safety study. Accident data for period of five years (2005-2011) collected from police records.

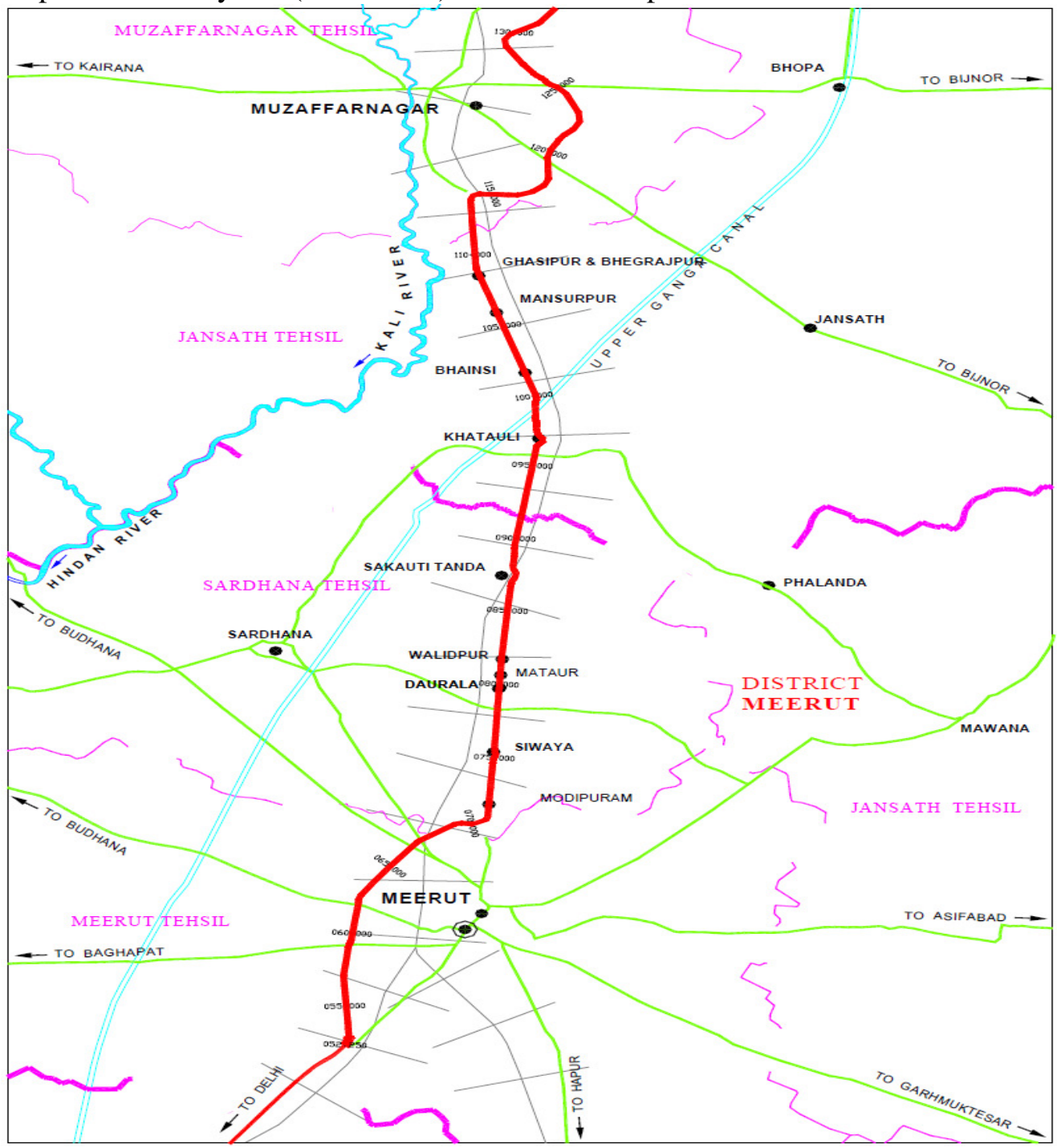

Figure 1. Study Area Route Map of NH-58. 


\subsection{Site Selection}

The stretch from Km 75.00 to Km 130.00 of National Highway 58 had been selected for candidate analysis. The selected highway stretch has been newly reconstructed and upgraded to four lane. The two important obligatory points on the study area are Meerut and Muzaffarnagar of the highway in the state of Uttar-Pradesh, India. The road stretch traverses through a flat and rolling terrain of mostly agricultural and urban settlement land. The route map is shown in Figure 1. This national highway is maintained and operated by National Highway Authority of India (NHAI).

\subsection{Description of Study Area}

The National Highway-58 originates from national capital New Delhi and goes up to Mana, near China boarder in Uttrakhand state. It serves as a life line to the hilly part of the state. The road is strategically important as being the shortest route from Delhi to international China boarder. The highway has length of $536 \mathrm{Km}$ of which $230 \mathrm{Km}$ length in plain and rest in the hilly terrain. The highway connects important religious destinations which attracting tourist from all over the country and world throughout the year. The highway has two-lane and four-lane stretches. Traffics on the highway are mixed in nature and comprises of heavy and light vehicles. The study road section is newly upgraded four-lane divided National Highway and opened for traffic. This road stretch is the best suited to conduct post opening road safety study for divided four-lane National Highway. The main settlements along the NH are Siwaya, Daurala, Sakauti, Jarouda, Khatauli, Bhainsi, Mansurpur, Bengrajpur, Janshath Bypass, Bhopa, and Sisauna. Earlier the road was passed through three major cities Meerut, Khatauli and Muzaffarnagar but these settlements are now bypassed during reconstruction. The road level has been raised with respect to nearby area. Maximum access roads have level difference. Route map of study section of National Highway-58 is shown in Figure 1.

\subsection{Details of Road Geometrics}

Main Carriageway is $7.00 \mathrm{~m}$ wide with $1.50 \mathrm{~m}$ paved and $2.00 \mathrm{~m}$ earthen shoulder on either side of the roadway. The median width is $5 \mathrm{~m}$ and raised type in general. A length 12.000 $\mathrm{Km}$ road has median width $8.5 \mathrm{~m}$ of depressed type. Service road of total length $7.680 \mathrm{Km}$ is having $5.50 \mathrm{~m}$ wide on the study section of $\mathrm{NH}$. Table 1 shows the road infrastructure details for the study area.

Table 1: Road Infrastructures Details

\begin{tabular}{|l|l|}
\hline Highway Features & Description/ Quantity \\
\hline Major Junctions & 07 numbers \\
\hline Major Bridges & 02 numbers (Over Major Ganga Canal \& Khatauli Escape Canal) \\
\hline Minor Bridges & 03 numbers at Km. 109.260, 115.250 \& 117.700. \\
\hline R O B & 02 numbers at Km. 87.583 \& 114.289. \\
\hline
\end{tabular}




\begin{tabular}{|l|l|}
\hline Underpasses & 05 numbers at $\mathrm{Km} 78.815,87.400,102.896,118.550 \& 122.175$. \\
\hline Culverts & 186 numbers \\
\hline Truck lay byes & 02 numbers \\
\hline Bus lay bays & 07 numbers \\
\hline Toll Plaza & 1 number at Km.75.990 \\
\hline
\end{tabular}

\section{MODEL DEVELOPMENT}

This section describes the approach used for developing the statistical model. The modeling objective consists of estimating the crash frequency of motor vehicle crashes for each transportation element. The units for these models were in number of crashes per year per segment of road section.

Given the nature of the data, a gamma modeling framework was used for developing models. This modeling framework is the preferred method for modeling non-negative and independent discrete events, such as motor vehicle crashes.

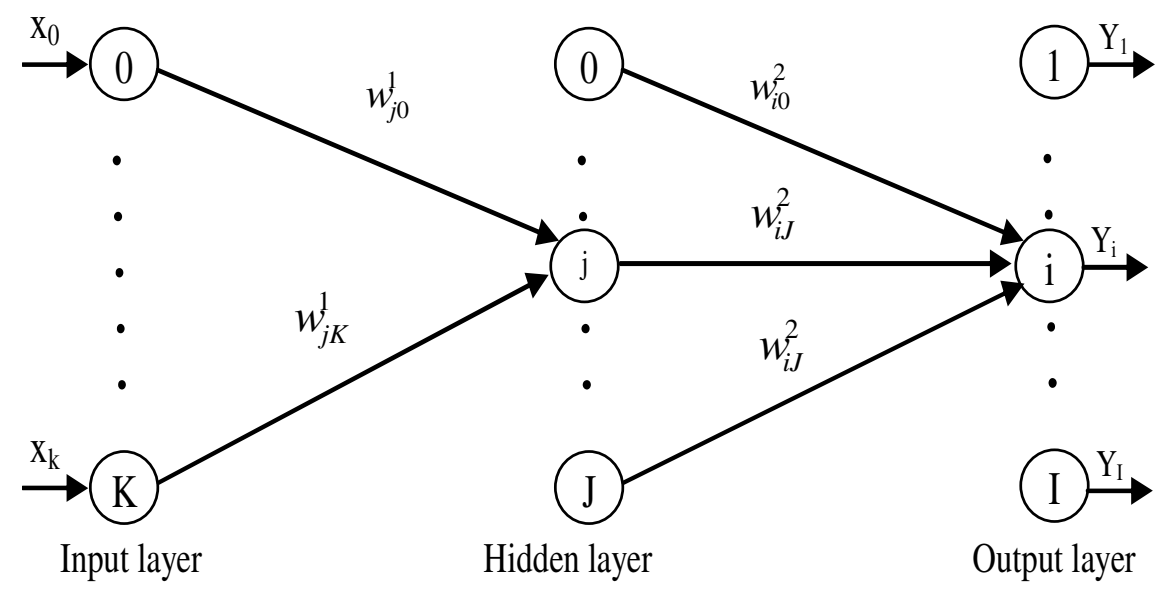

Figure 2. MLP Neural Network Architecture.

The multilayer perceptron (MLP) usually consists of three layers, as shown in Figure 1: Input layer, hidden layer, and output layer. In this figure, input layer has K nodes and a bias node (designated as Node 0 ), the hidden layer has $\mathbf{J}$ nodes and a bias node (designated as Node 0), and the output layer has I nodes and no bias node. The connections in the MLP are of the feed-forward type. That is, connections are allowed from a layer of a certain index to layers of a higher index. As from Figure 1, no connections are allowed from a layer of a certain index to a layer of lower index (i.e., feedback connections). Also, no connections are allowed among the nodes belonging to the same layer.

The MLP neural networks can operate in two distinct phases: the training phase and the testing phase. The training phase works as follows: given a collection of training data $\{x(1)$, $\mathrm{d}(1)\}, \ldots .,\{\mathrm{x}(\mathrm{p}), \mathrm{d}(\mathrm{p})\}, \ldots . .,\{\mathrm{x}(\mathrm{PT}), \mathrm{d}(\mathrm{PT})\}$, the objective is to map $\{\mathrm{x}(1)$ to $d(1)\}, \ldots \ldots,\{\mathrm{x}(\mathrm{p})$ to $\mathrm{d}(\mathrm{p})\}$, and eventually $\{\mathrm{x}(\mathrm{PT})$ to $\mathrm{d}(\mathrm{PT})\}$. 
The back-propagation learning algorithm is used to train the MLP. The procedures of a simple backpropagation algorithm starts with initializing all the weights $(\mathrm{w})$ and threshold $(\theta)$ levels of the network to small random numbers. Then calculate the actual output of the neurons in the hidden layer as:

$Y i(p)=f\left[\sum(i=1\right.$ to $\left.n) x i(p) * \operatorname{wij}(p)-\theta j\right]$, where $n$ is the number of inputs of neuron $j$ in the hidden layer. Next calculate the actual outputs of the neurons in the output layer as:

$\operatorname{yk}(\mathrm{p})=\mathrm{f}\left[\sum(\mathrm{j}=1\right.$ to $\left.\mathrm{m}) \operatorname{xjk}(\mathrm{p}) * \mathrm{wjk}(\mathrm{p})-\theta \mathrm{k}\right]$, where, $\mathrm{m}$ is the number of inputs of neuron $\mathrm{k}$ in the output layer.

Consider that an input patter $\mathrm{x}(\mathrm{p})$ applied across the input layer of the MLP. Then, to ensure that the output of the MLP is equal to $d(p)$, an error function of the following form is constructed:

$$
E(w)=\sum_{p=1}^{P T} \sum_{i=1}^{I}\left[d_{i}^{2}(p)-y_{i}^{2}(p)\right]^{2}
$$

Where, $E(w)=$ error function to be minimized,

$w \quad=$ weight vector,

$P T \quad=$ number of training patterns,

$I \quad=$ number of output nodes,

$d_{i}^{2}(p)=$ desired output of node $i$ when patter $p$ is introduced to the MLP, and

$y_{i}^{2}(p)=$ actual output of node $i$ when patter $p$ is introduced to the MLP, and

The objective is to change the weight vector $\mathrm{w}$ so that the above function is minimized. By minimizing the above error function, the actual output is in fact driven closer to the desired output. Assuming that the aforementioned error function is differentiable, optimization procedures can be applied to minimize it. One of these procedures is the gradient descent procedure, which changes the weight vector w by an amount that is proportional to the negative gradient.

That is, $\Delta w=-\eta \nabla E(w)$

Where, $\Delta w=$ change of weight vector,

$\eta=$ learning parameter, and

$\nabla E(w)=$ gradient vector $E(w)$ with respect to weight vector $\mathrm{w}$.

It can be shown that the equations that describe the change of the weights are as follows:

$$
\begin{aligned}
& \Delta w_{i j}^{2}=\eta \delta_{i}^{2}(p) y_{j}^{1}(p) \\
& \Delta w_{j k}^{1}=\eta \delta_{i}^{1}(p) x_{k}(p)
\end{aligned}
$$

Where, $\Delta w_{i j}^{2}=$ weight converging to the output layer,

$\Delta w_{i j}^{1}=$ weight converging to the hidden layer,

$\delta_{i}^{2}(p)=$ error term associated with output node $i$ due to presentation of input pattern $p$,

$\delta_{i}^{1}(p)=$ error term associated with output node $j$ due to presentation of input pattern

$p$

$y_{j}^{1}(p)=$ output of hidden node $j$ due to presentation of input pattern $p$, and

$x_{k}(p)=$ input component of index $k$ in input pattern. 
Learning algorithm consists of the main frame of an ANN. In the many learning algorithm, the most common ones are trainlm and trainbr. These two algorithms are called as Levenberg - Marguardt (LM). Tainlm, which has an algorithm that reduce memory requirements, is used when a set of learning is very large. This algorithm is the fastest of modern learning algorithm.

However, Bayesian Regulation (Br) - trainbr is a form of enhanced Tainlm algorithm. Trainbr algorithm is a learning method regulating bayessian. This method is a learning algorithm developed to improve the generalization skill of Levenberg - Marguardt.

\subsection{ANN Model Performance Measures:}

Different performance measues are used as the stopping criteria for the ANN tool. In this study for Levenberg - Marquardt, mean squared error with regularisation was the performance measure function. For Bayesian Regulation, sum of squared error was the performance measure function. Correlation coefficient was also used for investigating the model accuracy.

\subsection{Goodness of Fit Statistics:}

Schawarz's Bayesian Criterion (SBC)

SBC is associated with the number of parameters ( K ) and the sample size ( N ). Smaller the value of SBC, better is the fit of model to the data utilised. It is computed the following way: $S B C=\ln ($ Error Component $)+K \ln (N) / N$

\section{DATA ANALYSIS}

\subsection{Data Description}

With consideration given to variables applied in past models and data availability, data were obtained for estimating the crash prediction models. Accident records for five years from 2005 to 2010 were collected. Accident Count (AC) in per kilometre per year was taken as dependent variable in the prediction models.

The safety parameters included for safety study were Geometric Characteristics like Carriageway Width and Condition(CWC), Median Width Condition and its Openings(MWCO), Shoulder (Paved/Soft-Brick or Earthen)(SPSBE), Condition of Shoulder/Vegetation Control(CSVC), Side Drain Condition(SDC), Guard Rail Conditions(GCR), Road Markings (RM), Marker Post(MP), Horizontal Alignment(HA), Curve Warnings and Chevron Markings(CWCh), Other Warning and Advisory signs(OWA), Cross Drainage works(CD), Fly Over/Road over bridge/ Under Pass(FOU), Access Roads/Side Roads(ARSR), Junction(Jn), Overhead Structures/Hoardings(OSH), Land Use(LU) and Traffic Characteristics like Traffic Volume(TV), Percentage of Cars (PtC), Percentage of 
Trucks(PtT) and Spot Speed(SS). The selected road segment was divided into $200 \mathrm{~m}$ each to carry out extensive safety assessment of highway environment, which lead to a total number (N) of 275 data sets. All identified safety parameters and their conditions had been noted in the survey Performa. Road safety data had been collected for both direction of the divided four-lane National Highway 58 in between $\mathrm{Km} 75.00$ and $\mathrm{Km}$ 130.00.

\subsection{ANALYSIS OF RESULTS}

Statistical summary of the variables are represented in Table 2. Parameters like SPSPBE, SDC, MWCO, FOU \& MP showed less correlation to independent variable AC and were more inter correlated, leading to the omission of these insignificant variables in the modeling.

The Neural Network Toolbox from the MATLAB library was used to train, validate and test the dataset. The training algorithms were LM and Br functions. These algorithms starts from an arbitrary set of interconnection weights randomly chosen from a uniform distribution of values between 0 and 1 . The algorithm then tries to minimize the differences between the network output and the observed outputs. All runs had been carried out with a maximum number of epochs (1000 epochs). For both the algorithms the performance error criterion was set to zero as goal value. For LM algorithm maximum gradient and maximum mu were set to $1 \mathrm{e}+10$ and $1 \mathrm{e}+300$ respectively with validation check stop criteria up to 30 . Both maximum gradient and max. mu were set to $1 \mathrm{e}+10$ for $\mathrm{Br}$ algorithm with validation checks up to 300 .

The input layer neurons that represent sixteen different explanatory variables, and the output layer has one neuron representing dependent variable - accident count. All transfer functions at the hidden layer and the output layer are hyperbolic tangent sigmoid transfer functions. This type of transfer function has the following form:

$$
g(n e t)=(1-\exp (-\alpha \text { net })) /(1 \mp \operatorname{xp}(-\alpha \text { net }))
$$

Where net is the net input to a node and $\alpha$ is a positive slope parameter that gives different looks to the sigmoid function. To select the number of layers and hidden nodes, an experiment with different values (5 to 20 layers in increments of 5 and 8 to 48 hidden nodes with increments of 16) was carried out. The number hidden nodes that gives the best network performance; four criteria - error component, SBC, Chi-square and correlation coefficient was selected. 
Table 2: Statistical Summary of the Parameters.

\begin{tabular}{|c|c|c|c|c|}
\hline Variables & N & Mean & Variance & $\begin{array}{c}\text { Standard } \\
\text { Deviation }\end{array}$ \\
\hline SS & 275 & 61.6464 & 15.135 & 3.89042 \\
\hline TV & 275 & 9.9243 & 0.002 & 0.04121 \\
\hline PtC & 275 & 8.3342 & 0.016 & 0.1258 \\
\hline PtT & 275 & 9.2011 & 0.005 & 0.06881 \\
\hline CWC & 275 & 2.0327 & 0.441 & 0.66372 \\
\hline CSVC & 275 & 2.5891 & 1.404 & 1.18471 \\
\hline GCR & 275 & 0.1382 & 0.134 & 0.36623 \\
\hline RM & 275 & 1.8945 & 0.233 & 0.48308 \\
\hline HA & 275 & 1.1964 & 0.158 & 0.39797 \\
\hline CWCh & 275 & 0.12 & 0.106 & 0.32555 \\
\hline OWA & 275 & 0.1527 & 0.13 & 0.36038 \\
\hline CD & 275 & 0.3382 & 0.225 & 0.47395 \\
\hline ARSR & 275 & 3.1673 & 26.432 & 5.14118 \\
\hline Jn & 275 & 0.2655 & 0.218 & 0.46647 \\
\hline OSH & 275 & 0.1345 & 0.117 & 0.34186 \\
\hline LU & 275 & 4.0582 & 1.164 & 1.07911 \\
\hline AC & 275 & 0.4857 & 0.131 & 0.36176 \\
\hline
\end{tabular}

Degree of freedom (df) can be calculated as, $\mathbf{d f}=275-(17$ variables $)=\mathbf{2 5 8}$.

Table 3: Performance and Characteristics of Different Models.

\begin{tabular}{|c|c|c|c|c|c|c|c|c|c|}
\hline Models & SBC & $\mathrm{e}$ & $\mathrm{K}$ & $\mathrm{N}$ & Layers & Neurons & $\begin{array}{l}\text { Training } \\
\text { Function }\end{array}$ & $\chi^{2}$ & $\begin{array}{c}\text { Critical } \\
\chi^{2}\end{array}$ \\
\hline ANN1 & -2.089 & 0.089 & 16 & 275 & 5 & 8 & LM & 27.551 & \multirow{8}{*}{295.347} \\
\hline ANN2 & -1.854 & 0.113 & 16 & 275 & 10 & 16 & LM & 33.538 & \\
\hline ANN3 & -2.135 & 0.085 & 16 & 275 & 15 & 32 & LM & 38.602 & \\
\hline ANN4 & -1.028 & 0.258 & 16 & 275 & 20 & 48 & LM & $4.605 \mathrm{E}+09$ & \\
\hline ANN5 & 2.527 & 9.030 & 16 & 275 & 5 & 8 & $\mathrm{Br}$ & 23.130 & \\
\hline ANN6 & 2.200 & 6.510 & 16 & 275 & 10 & 16 & $\mathrm{Br}$ & 23.725 & \\
\hline ANN7 & 1.378 & 2.860 & 16 & 275 & 15 & 32 & $\mathrm{Br}$ & 23.971 & \\
\hline ANN8 & 2.427 & 8.170 & 16 & 275 & 20 & 48 & $\mathrm{Br}$ & 26.206 & \\
\hline
\end{tabular}

Note: SBC, Schawarz's Bayesian Criterion; e, error component; K, number of parameters; $\mathrm{N}$, the number of samples; LM, Levenberg - Marquardt; Br, Bayesian Regulaisation; $\chi^{2}$, chi square. 
Results in Table 3 revealed the accident count was predicted efficiently from models ANN3 and ANN7. The SBC values are -2.135 and 1.378, smaller the value better is the model. Chi-square value of the model is also lesser than the Critical chi-square value for all the models except for ANN4 model, supporting the acceptance criterion of the models.

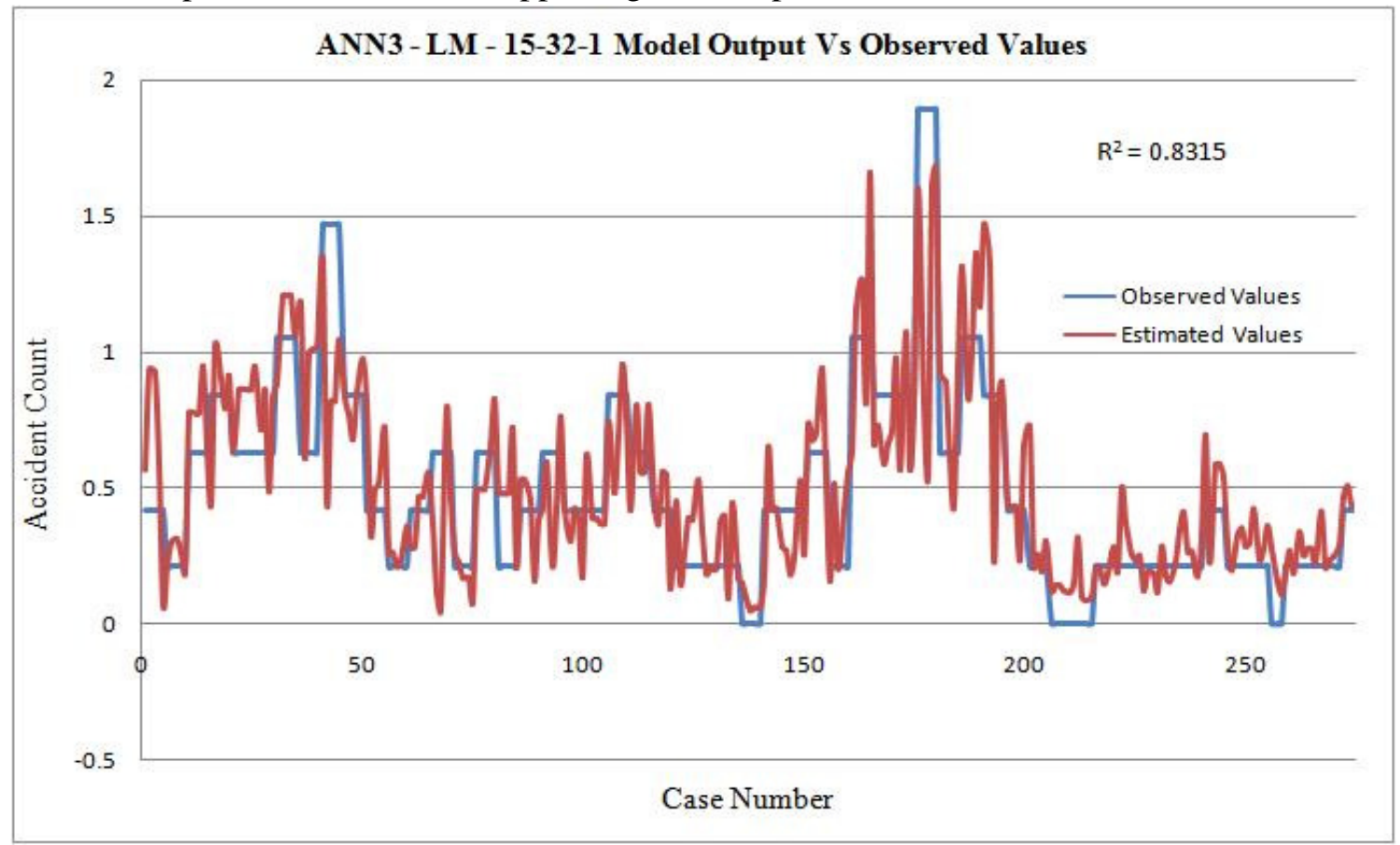

Figure 3. ANN3 Model Output Results.

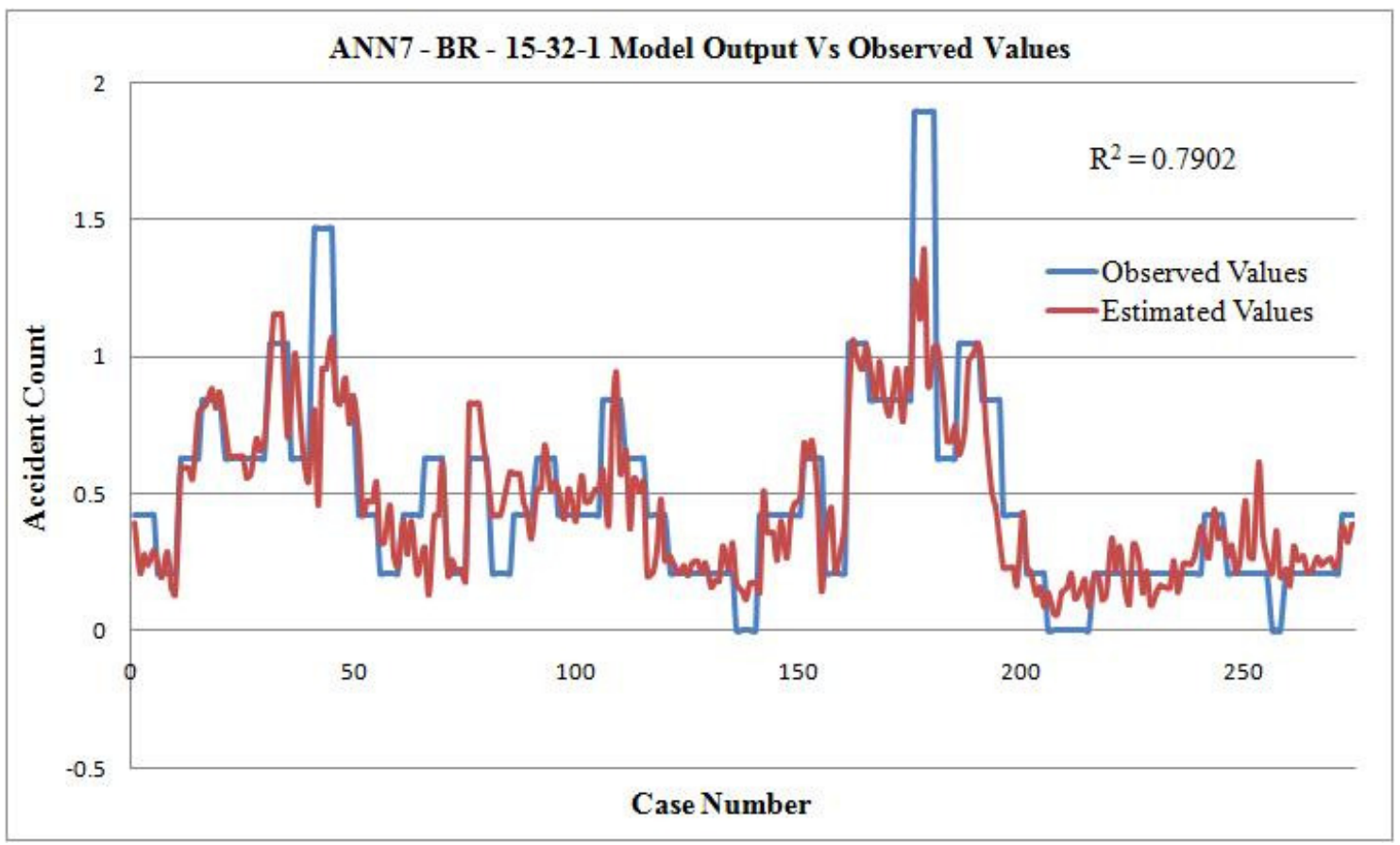

Figure 4. ANN7 Model Output Results. 


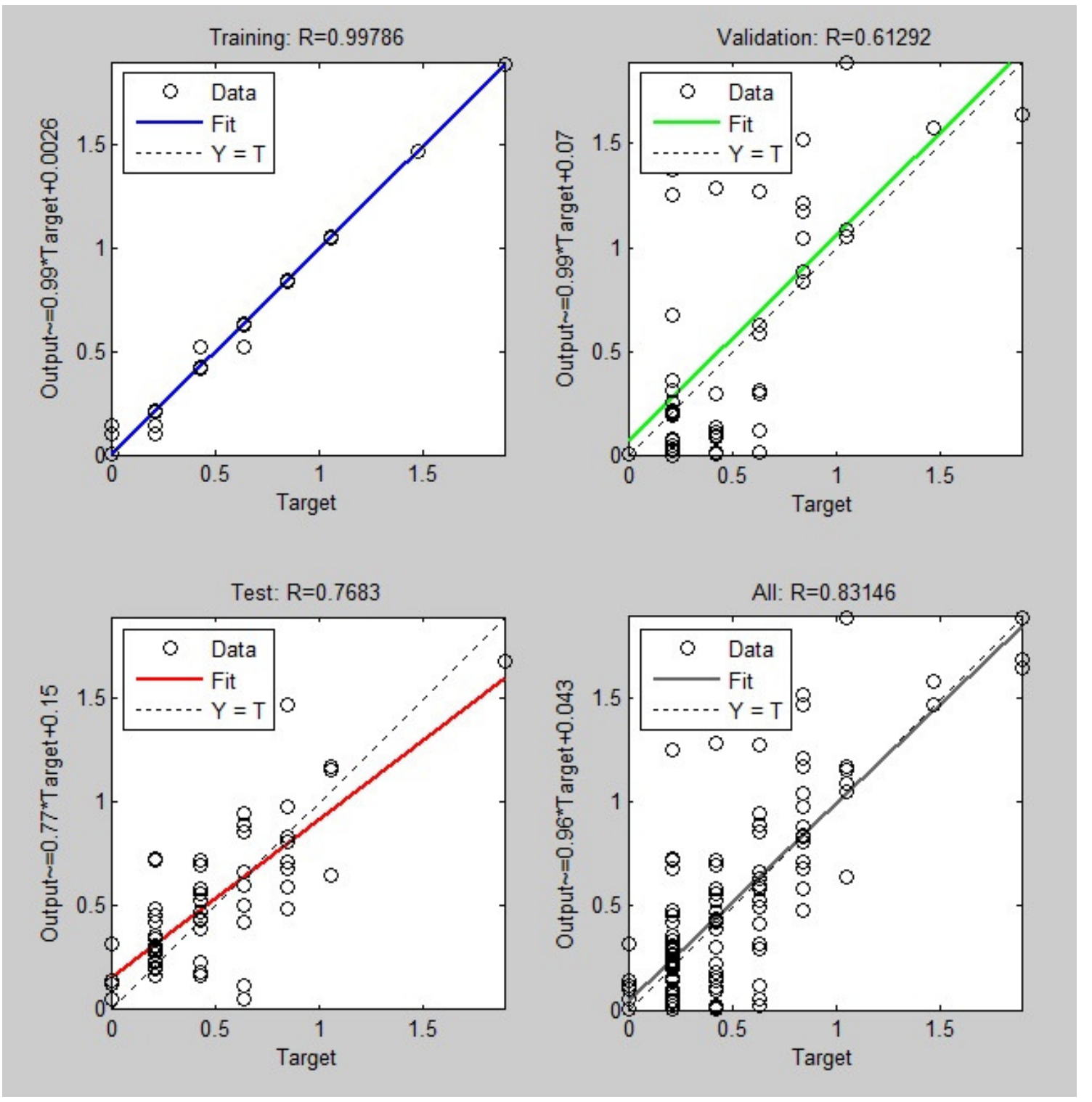

Figure 5. ANN3 Model Correlation Coefficient Results.

Consistent with the concept of exposure to risk of safety, an aggregate relationship between accident count and roadway geometrics, physical roadway furnitures were explored by ANN models and their outputs plotted against the true values are as shown in Figure 3 and 4. The overall coefficient of correlation $\left(\mathrm{R}^{2}\right)$ also supported the goodness of fit. Figure 5 show ANN3 model gave $\mathrm{R}^{2}=0.8315$ compared to the Bayesian regular ANN7 model with $\mathrm{R}^{2}=$ 0.7902 . 


\section{CONCLUSIONS}

This paper presents a soft computational analysis tool for the accurate prediction of crashes on National Highways in India. After careful application and assessment of ANN models, accompanied by detailed examination of the road crash models, following conclusions are drawn.

The ANN for modeling of road crashes was the most appropriate quick modeling tool for collected accident data. The ANN count model is a flexible model that can fit very effectively to the given data, and is relatively new in transportation safety literature.

Examination of modeling results suggests that the performance of ANN3 \& ANN7 were highly accurate for further crash analysis. Further chi-square analysis of the different models also revealed the model accuracy was higher in crash prediction except for ANN4 model.

Hence for efficient and quick analysis of the available dataset whether the dataset is large or having statistical deficiencies, ANN is an efficient tool for the analysis of such models and prioritization of the sites can be made easily from the model analysis.

\section{REFERENCES}

[1] Abdel-Aty, M., and Abdelwahab, H., Analysis and Prediction of Traffic Fatalities Resulting From Angle Collisions Including the Effect of Vehicles' Configuration and Compatibility. Accident Analysis and Prevention, 2003.

[2] Abdelwahab, H. T. and Abdel-Aty, M. A., Development of Artificial Neural Network Models to Predict Driver Injury Severity in Traffic Accidents at Signalized Intersections. Transportation Research Record 1746, Paper No. 01-2234.

[3] Abraham, Intelligent Systems: Architectures and Perspectives, Recent Advances in Intelligent Paradigms and Applications, Abraham A., Jain L. and Kacprzyk J. (Eds.), Studies in Fuzziness and Soft Computing, Springer Verlag Germany, Chapter 1, pp. 1-35, 2002.

[4] Breiman,L., 2001. Statistical modeling: the two cultures. Statistical Science 16,199-231.

[5] Buzeman, D. G., Viano, D. C., \& Lovsund, P., Car Occupant Safety in Frontal Crashes: A Parameter Study of Vehicle Mass, Impact Speed, and Inherent Vehicle Protection. Accident Analysis and Prevention, Vol. 30, No. 6, pp. 713-722, 1998.

[6] Carpenter, G.A., S. Grossberg, N. Markuzon, J.H. Reynolds, and D.B.Rosen. Fuzzy ARTMAP: A Neural-Network Architecture for Incre-mental Supervised Learning of Analog Multidimensional Maps. IEEE Transactions on Neural Networks, Vol. 3, 1992, pp. 698-713.

[7] Cheng, B.,Titterington, D.M., 1994. Neural networks: a review from a statistical perspective. Statistical Science 9,2-54.

[8] DeTienne, K.B., Detienne, D.H., Joshi, S.A., 2003.Neural networks as statistical tools for business researchers. Organizational Research Methods 6(2),236-265.

[9] Eubank, R.L., 1988. Spline Smoothing and Non parametric Regression of Statistics, Text books and Monographs, vol.90. Marcel Dekker.

[10] Flexer, A., 1996. Statistical evaluation of neural network experiments: minimum requirements and current practice. In: Proceedings of the 13th European Meeting on Cybernetics and Systems Research, Austrian Society for Cybernetic Studies, Vienna, vol. 2, 
pp.1005- 1008 .

[11] Grossberg, S. Adaptive Pattern Recognition and Universal Recording II:Feedback, Expectation, Olfaction, and Illusions. Biological Cybernetics, Vol. 23, 1976, pp. 187-202.

[12] Gupta, A., Lam, M.S., 1996. Estimating missing values using neural networks. Journal of the Operational Research Society 47 (2) , $229-239$.

[13] Hashemi, R.R., LebBanc, L.A., Rucks, C.T., Shearry, A.,1995. A neural network for transportation safety modeling. Expert Systems with Applications 9 (3), 247 - 256.

[14] Hand ,D.J., 2000. Data mining, new challenges for statisticians. Social Science Computer Review 18 (4), 442 - 449.

[15] Hanson, S.J., 1995. Back - propagation: some comments and variations. In: Rumelhart, D. E.,Yves, C.(Eds.), Back - propagation: Theory, Architecture, and Applications. Lawrence Erlbaum, NJ, pp.237-271.

[16] Karlaftis, M.G., Vlahogianni, E.I., 2011. Statistical Methods versus Neural Networks in Transportation research: Differences, Similarities and some insights. Transportation Research Part C 19, 387 - 399.

[17] Kuan,Ch.- M., White, H., 1994. Artificial neural networks: an econometric perspective. Econometric Reviews 13 (1), 1 - 9.

[18] Li, X., Lord, D., Zhang, Y., Xie, Y., 2008. Predicting motor vehicle crashes using support vector machine models. Accident Analysis \& Prevention 40 (4), 1611 - 1618.

[19] Miao, C., Ajith, A., Marcin, P., 2005. Traffic Accident Analysis Using Machine Learning Paradigms. Informatica 29, 89 - 98.

[20] Nicholls, D., 1999. Statistics into the 21st century. Australia \& New Zealand, Journal of Statistics 41 (2), 127 - 139.

[21] Principe, J.C., Euliano, N.R., Lefebvre, C.W., 2000. Neural and Adaptive Systems: Fundamentals Through Simulations. John Wiley and Sons Inc.

[22] Parida, M, Jain, S.S., \& Landge, V.S., "ANN versus stochastic model for accident frequency prediction" Safety Science, Elsevier Publications.

[23] Ripley, B.D., 1996. Pattern Recognition and Neural Networks. Cambridge University Press, Cambridge.

[24] Sarle, W.S., 1994. Neural networks and statistical models. In: Proceedings of the Nineteenth Annual SAS Users Group International Conference (April 1 - 13).

[25] Xie, Y., Lord, D., Zhang, Y., 2007. Predicting motor vehicle collisions using Bayesian neural network models: an empirical analysis. Accident Analysis \& Prevention 39 (5), 922 -933 . 